\title{
Evolution of the vertebrate pth2 (tip39) gene family and the regulation of PTH type 2 receptor (pth2r) and its endogenous ligand pth2 by hedgehog signaling in zebrafish development
}

\author{
Poulomi Bhattacharya, Yi Lin Yan ${ }^{1}$, John Postlethwait ${ }^{1}$ and David A Rubin \\ Department of Biological Sciences, Illinois State University, Normal, Illinois 61701, USA \\ ${ }^{1}$ Institute of Neuroscience, University of Oregon, Eugene, Oregon 97403, USA \\ (Correspondence should be addressed to D A Rubin; Email: adavid@ilstu.edu)
}

\begin{abstract}
In mammals, parathyroid hormone (PTH), secreted by parathyroid glands, increases calcium levels in the blood from reservoirs in bone. While mammals have two PTH receptor genes, PTH1R and PTH2R, zebrafish has three receptors, $p t h 1 r, p t h 2 r$, and $p t h 3 r$. PTH can activate all three zebrafish Pthrs while PTH2 (alias tuberoinfundibular peptide 39, TIP39) preferentially activates zebrafish and mammalian PTH2Rs. We know little about the roles of the PTH2/PTH2R system in the development of any animal. To determine the roles of PTH2 and PTH2R during vertebrate development, we evaluated their expression patterns in developing zebrafish, observed their phylogenetic and conserved synteny relationships with humans, and described the genomic organization of $p t h 2$, $p t h 2 r$, and $p t h 2 r$ splice variants. Expression studies showed that pth 2 is expressed in cells adjacent to the ventral part of the posterior
\end{abstract}

tuberculum in the diencephalon, whereas $p t h 2 r$ is robustly expressed throughout the central nervous system. Otic vesicles express both pth 2 and $p t h 2 r$, but heart expresses only pth 2 . Analysis of mutants showed that hedgehog $(H h)$ signaling regulates the expression of pth 2 transcripts more than that of nearby gnrh2-expressing cells. Genomic analysis showed that a lizard, chicken, and zebra finch lack a PTH2 gene, which is associated with an inversion breakpoint. Likewise, chickens lack PTH2R, while humans lack PTH3R, a case of reciprocally missing ohnologs (paralogs derived from a genome duplication). The considerable evolutionary conservation in genomic structure, synteny relationships, and expression of zebrafish pth2 and $p$ th $2 r$ provides a foundation for exploring the endocrine roles of this system in developing vertebrate embryos.

Journal of Endocrinology (2011) 211, 187-200

\section{Introduction}

Parathyroid hormone (PTH), PTH2, and PTH-like hormone (PTHLH, alias PTHRP, PTH-related protein) are members of a small gene family (Papasani et al. 2004). Although PTH is an endocrine hormone that regulates serum calcium, PTHLH regulates patterning of chondrogenic and odontogenic tissues in mammals (Miao et al. 2002, Schipani \& Provot 2003). Zebrafish has two co-orthologs of Pth (Gensure et al. 2004, Hogan et al. 2005) that appear to have originated during genome duplication at the base of teleost radiation (Postlethwait et al. 1998, 1999, Taylor et al. 2003, Amores et al. 2004, Hoegg et al. 2004, Jaillon et al. 2004). In humans, PTH provides an important therapy for osteoporosis (Swarthout et al. 2002) and deregulation of PTHLH is responsible for most instances of humoral hypercalcemia of malignancy (high calcium levels in the blood associated with breast, lung, and myeloma cancers; Mangin et al. 1988, Guerreiro et al. 2007). Despite the importance of PTH and PTHLH for human health and disease, the functions of PTH2 are not well understood in any species.
The expression patterns of PTH gene family members are distinct. In mammals, PTH is expressed primarily in the parathyroid glands with lower levels detected in the hypothalamus and pituitary (Fraser et al. 1990, 1991, Harvey \& Hayer 1993) and thymus (Tucci et al. 1996, Postlethwait et al. 1999, Günther et al. 2000). In contrast, PTHLH is expressed in many mammalian cell types, including cartilage, bone, mammary glands, teeth, skin, pancreatic islets, and smooth muscles in the cardiovascular system and is widely expressed in neurons of cerebral cortex, hippocampus, and cerebellum (Merendino et al. 1986, Weir et al. 1990, Weaver et al. 1995, Wysolmerski \& Stewart 1998, Broadus \& Nissenson 2006). Whereas PTH2 is expressed in the subparafascicular area and in the medial paralemniscal nucleus of the central nervous system (CNS) in 3-day-old macaque, nothing is known about its expression in human brain (Bago et al. 2009). Rat CNS expresses Pth2 in posterior ventral thalamic areas, medial paralemniscal nucleus, and dorsal and dorsolateral hypothalamus (Dobolyi et al. 2003a,b), as in other mammals, suggesting roles substantially different from the roles that other PTH paralogs play in skeletal 
development and maintenance. Zebrafish, however, has duplicate orthologs of the human PTH gene (Gensure et al. 2004) called pth $1 a$ and pth $1 b$ that are expressed along the lateral line before neuromast migration and in the neuromasts, as well as in the ventral neural tube (Hogan et al. 2005). Our previous study showed generalized expression of pth 2 in the forebrain-midbrain boundary and in heart in 2-day-old embryos (Papasani et al. 2004). Here, we report the genomic structure of zebrafish pth2 and the results of conserved synteny investigations among zebrafish, human, chicken, and lizard chromosomes, showing that PTH2 was lost in the lineage leading to lizards and birds. In addition, we provide a detailed analysis of pth2 expression in zebrafish embryos and its regulation by shh.

PTH, PTH2, and PTHLH interact with the G-proteincoupled receptors, PTH1R, PTH2R, and PTH3R (Rubin \& Jüppner 1999a,b). PTH and PTHLH bind and activate PTH1R nearly equivalently (Gardella \& Jüppner 2001). Although PTH partially activates PTH2R (Mannstadt et al. 1999, Usdin et al. 1999b), PTH2 is likely the endogenous PTH2R ligand (Hoare 2000, Hoare et al. 2000, John et al. 2002). Functional in vitro studies show that zebrafish Pth3r

B
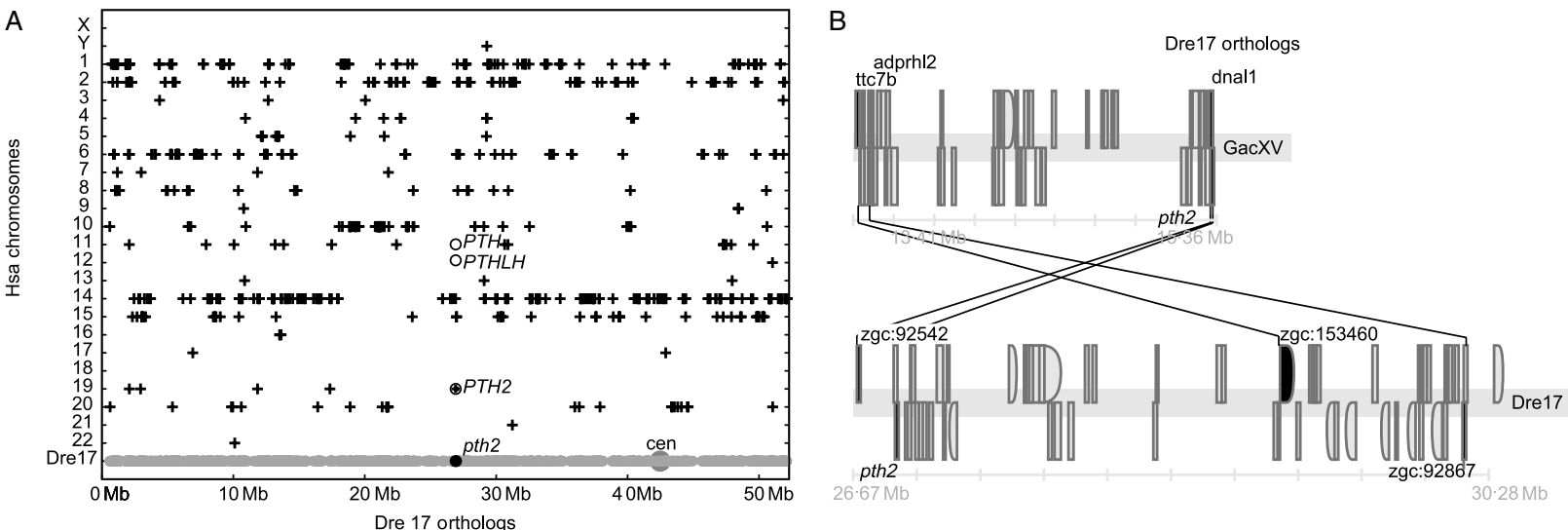

C
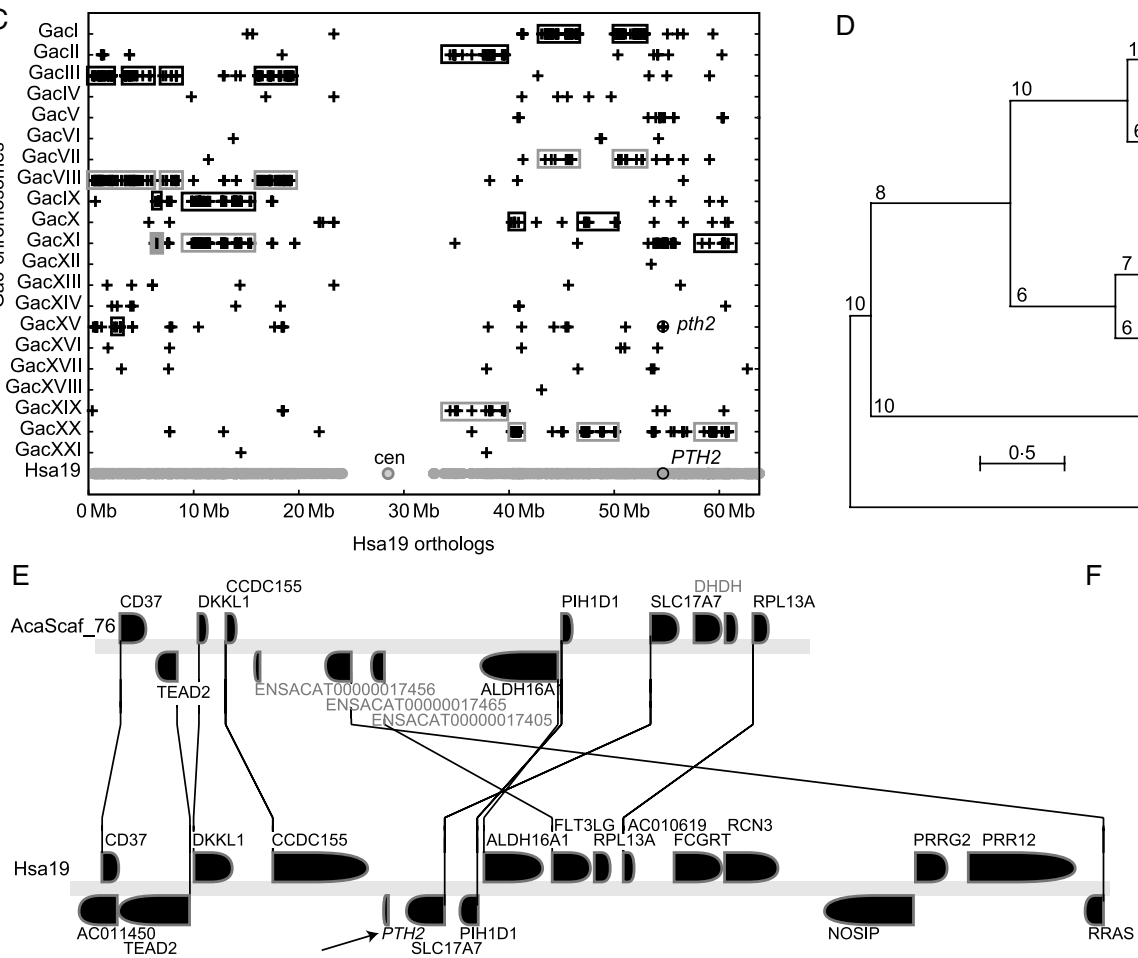

Hsa19

p12

q12

q13.2

D
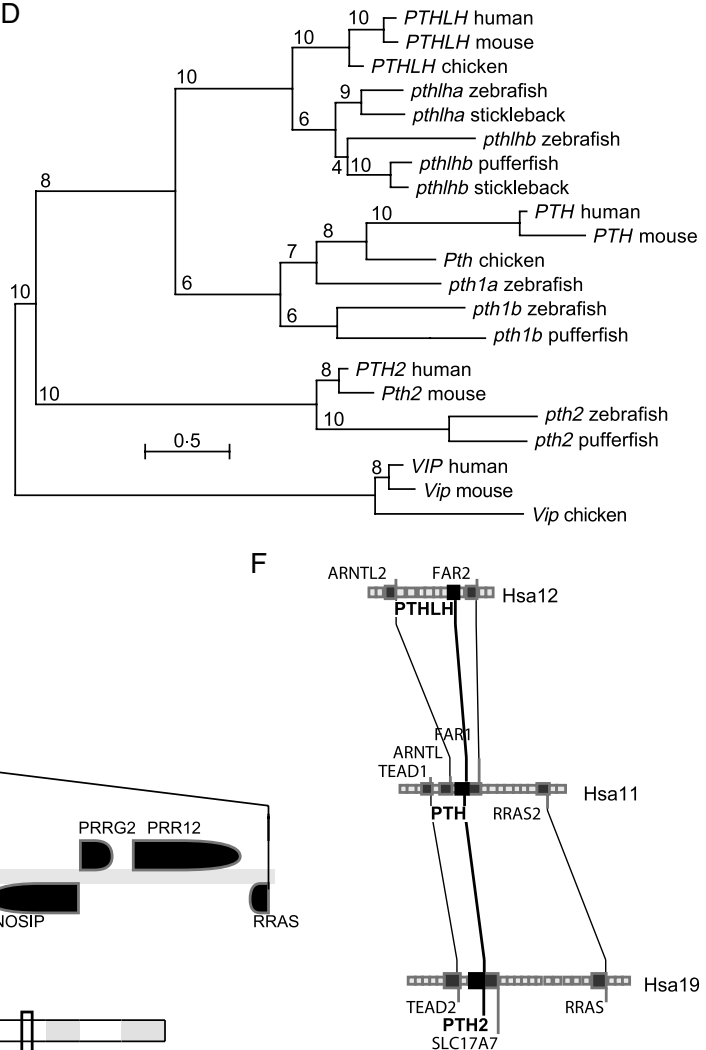

Journal of Endocrinology (2011) 211, 187-200

www.endocrinology-journals.org 
expressed in COS-7 cells binds Pthlh and Pth and shows preferential activation by Pthlh (Rubin \& Jüppner 1999a). We previously observed $p$ th $2 r$ expression throughout the developing zebrafish brain at 48 and $72 \mathrm{~h}$ (Papasani et al. 2004) and here provide detailed expression profiles over time. We describe the conserved genomic structure of $p t h 2 r$, with its conserved syntenies among zebrafish, human, and chicken chromosomes showing that loss of chicken PTH2R was associated with chromosome breakpoints. In addition, we isolated a novel splice variant (SV\#19) of the original gene (pth2r). Our aim was to obtain detailed information regarding the genomic structure of $p t h 2 r$ that would illuminate our understanding of the human $P T H 2 / P T H 2 R$ system.

\section{Materials and Methods}

\section{Zebrafish}

$\mathrm{AB}$ wild-type zebrafish and smo and syu mutants were obtained from the Oregon Fish Facility. Embryos were incubated at $28^{\circ} \mathrm{C}$ (Kimmel et al. 1995). Embryos used for in situ hybridization on whole-mounts and cryosections were treated with $0 \cdot 003 \%$ 1-phenyl-2-thiourea before $24 \mathrm{hpf}$ to inhibit pigmentation. All protocols were approved by local IACUC committees.

\section{$R N A$ extraction and RT-PCR}

Each RT-PCR used 22 whole embryos. Embryos were homogenized in Tri Reagent (Sigma-Aldrich); at least two independent total RNA preps were extracted following the manufacturer's protocol and treated with DNase I (Roche). After determining RNA concentration and quality by spectrophotometer and agarose gel electrophoresis, cDNA was synthesized using $5 \cdot 0 \mu \mathrm{g}$ total RNA ( $25 \mu$ l total reaction volume as described previously (Rubin \& Jüppner 1999a, Rubin et al. 1999, Shoemaker et al. 2006)) with oligo (dT) primers using SuperScript II reverse transcriptase (Invitrogen) following the manufacturer's instructions. Gene-specific primers (Supplementary Table, see section on supplementary data given at the end of this article) were used to perform PCR as described (Papasani et al. 2004). To control for genomic DNA amplification, all RT-PCRs used DNasetreated RNA and the resulting amplicons crossed multiple introns. The amplicons were compared (Blast and Aligned) to gDNA and no gDNA contamination was observed (Supplementary Figure 1, see section on supplementary data given at the end of this article).

\section{Rapid amplification of $c D N A$ ends and DNA sequencing}

Splice variants were isolated by rapid amplification of cDNA ends (5'-RACE) as described (Rubin et al. 1999). In short, total zebrafish RNA was obtained using the micro-RNA isolation kit following the manufacturer's guidelines (Promega). To identify the $5^{\prime}$-end of the cDNA encoding PTH2, $\sim 1.0 \mu \mathrm{g}$ DNAse-treated total RNA from zebrafish was reverse transcribed using Omniscript II reverse transcriptase (Qiagen) and a gene-specific reverse primer (zPTH2-3ut\#1; Table 1). One-tenth of the RT-PCR product was used for an initial PCR consisting of reverse zPTH2-3ut\#2, forward zPTH2-5ut\#2, and Platinum Taq DNA polymerase (Invitrogen), with the following reaction profile: initial denaturation at $94^{\circ} \mathrm{C}$ for $3 \mathrm{~min}$ and 35 cycles with denaturation at $94^{\circ} \mathrm{C}$ for $1 \mathrm{~min}$, annealing at $54^{\circ} \mathrm{C}$ for $1 \mathrm{~min}$, polymerization at $72{ }^{\circ} \mathrm{C}$ for $2 \mathrm{~min}$, and final extension at $72{ }^{\circ} \mathrm{C}$ for $10 \mathrm{~min}$. A nested PCR using $2 \mu \mathrm{l}$ of the initial PCR product was performed using reverse zPTH2-3ut\#2 and forward zPTH2-5ut\#3 following

Figure 1 Conserved synteny analysis for pth2. (A) Dot plot showing zebrafish chromosome Dre17 across the bottom with the position of pth2 and the centromere (cen) marked. Directly above each gene on Dre17 (gray dots), the figure plots a cross on the human chromosome that carries the ortholog of each zebrafish gene. Human chromosomes containing PTH2, PTH, and PTHLH are indicated with circles. The plot shows little conservation of synteny between Dre17 and Hsa19, the site of PTH2, but substantial conservation of syntenies with Hsa14. (B) Conserved syntenies around zebrafish pth2 with the stickleback region on linkage group XV showing shared pairs of orthologs (connecting lines). (C) Dot plot comparing Hsa19 to stickleback chromosomes. Most regions of Hsa19 have two clear regions of conserved synteny with stickleback, which are surrounded by pairs of rectangles, paralogons resulting from the teleost genome duplication event. The exception is the region around pth2, which has no clear pair of co-orthologous chromosome segments, suggesting substantial chromosome rearrangement in the fish lineage with respect to the human lineage. (D) Maximum likelihood tree. Bootstrap numbers are of ten replicates. (E) Conserved syntenies for the human region around PTH2 compared with the anole lizard Anolis carolinensis. (F) Examination of paralogous chromosomes in the human genome show that PTH, PTH2, and PTHLH occupy paralogous chromosome segments. The top row shows the lizard scaffold_76 and its orthologous region in human in the next line down. An arrow indicates the position of PTH2 and an arrowhead indicates the site of the inversion breakpoint. The location of the human chromosome segment on Hsa19 is indicated on the idiogram below. Abbreviations and accession numbers: pth2 zebrafish, NM_212949 and AY306196; PTHLH human, J03580; PTHLH mouse, M60056; PTHLH chicken, X52131; PTHLH zebrafish, NM_001024627; PTHLH stickleback, ENSGACT00000000765; PTHLH zebrafish, NP_001036789; PTHLH pufferfish, AJ249391; PTHLH stickleback, ENSGACG00000004317; PTH human, NM_000315; PTH mouse, NM_020623; PTH chicken, M36522; PTH1A zebrafish, NM_212950; PTH1B zebrafish, NM_212949; PTH1 pufferfish, ENSTRUG00000008960; PTH2 human, NP_848544; PTH2 mouse, NP_444486; PTH2 pufferfish, ENSTNIG00000000280; VIP human, NP_003372; VIP mouse, BAB31301; VIP chicken, AAA87896. Anolis lizard genes and orthologs: ENSACAT00000017404, ALDH16A1; ENSACAT00000017405, FLT3LG; ENSACAT00000017456, SLC1A5 (19_47.28 Mb); ENSACAT00000017465, RRAS; ENSACAT00000017524, TEAD2; ENSACAT00000017351, RPL13A; ENSACAT00000017352, DHDH (Hsa19_49.44 Mb); ENSACAT00000017368, DHDH; ENSACAT00000017389, SLC17A7; ENSACAT00000017394, PIH1D1; ENSACAT00000017478, CCDC155; ENSACAT00000017480, DKKL1; ENSACAT00000017537, CD37; ENSACAT00000017456, FLT3LG; ENSACAT00000017405, RRAS. 
the same reaction profile. The $5^{\prime}$-RACE amplicons were electrophoresed through a $2 \%$ agarose gel containing ethidium bromide, purified, ligated to pGEM-Teasy (Promega) and named zPTH2-5'-RACE/pGEMT (Rubin et al. 1999), and used to transform Escherichia coli TOP10 cells (Invitrogen). Bacterial colonies were screened by PCR using gene-specific primers. At least two independent plasmids containing pth2 cDNAs were purified by miniprep (Invitrogen) and sequenced in duplicate according to the manufacturer's protocols (ABI, Perkin-Elmer Corp., Foster City, CA, USA). Orientations were determined after resequencing cDNA amplicons and confirmed using zebrafish Ensembl (www.ensembl.org).

\section{Genomic analysis for pth2 and pth2r}

To investigate conserved syntenies between zebrafish pth $2 / p t h 2 r$ and human PTH2/PTH2R, we used the Synteny Database (Catchen et al. 2009; http://teleost.cs.uoregon.edu/ synteny_db/). In Fig. 1A, along the bottom of the dot plot the gray dots represent genes in order along zebrafish (Danio rerio, Dre) chromosome 17 (Dre17), which contains pth2. The plot places a cross on the chromosome appropriate for the location of each zebrafish gene's human ortholog, so the horizontal gene order corresponds to the zebrafish chromosome. Open circles show positions of pth2, the human (Homo sapiens, Hsa) PTH2 (Hsa19), and its paralogs, $P T H$ (Hsa11) and PTHLH (Hsa12). For phylogenetic analysis sequences were aligned by Multiple Sequence Comparison by Log-Expectation (MUSCLE, http://www.ebi.ac.uk/Tools/ muscle/index.html) and subjected to maximum likelihood analysis (http://atgc.lirmm.fr/phyml/; Guindon \& Gascuel 2003, Guindon et al. 2005).

\section{In situ hybridization}

At least two independent whole-mount in situ hybridizations were performed using 20-30 embryos for each complementary RNA (cRNA) probe to ensure reproducibility. In addition, in situ hybridizations for control (sense RNA) and experimental embryos were conducted in parallel to minimize variances between days. The synthesis of cRNA probes followed published protocols: pth2 (Papasani et al. 2004), gnrh2 (Gopinath et al. 2004), gh1 (Herzog et al. 2004), and $v m h c$ and $m y l 7$ (Yelon et al. 1999). To synthesize the pth 2 cRNA probe, $p$ th $2 / \mathrm{pGEMT}$ was linearized with Mfe 1 and transcribed with Sp6 polymerase using the digoxigenin (DIG) RNA labeling kit following the manufacturer's instructions (Roche Applied Science). The pth 2 probe corresponded to bases 256-786 of accession number AY306196 (Supplementary Figure 1, see section on supplementary data given at the end of this article). To synthesize the $p t h 2 r$ cRNA probe, $p t h 2 r / p C R I I$ was linearized using BamHI and transcribed with Sp6 polymerase using the DIG RNA labeling kit as described above. The $p t h 2 r$ probe corresponded to bases 940-2429 of accession number NM_131377. Sense probes (control) were utilized to observe non-specific expression and compared to their previously verified cRNA expression patterns (pth2 (Papasani et al. 2004), gnrh2 (Gopinath et al. 2004), gh1 (Herzog et al. 2003,2004), vmhc, and myl7 (Yelon et al. 1999)).

Embryos were cryosectioned and used for in situ hybridization as described (Rodriguez-Mari et al. 2005). For pth2 and gnrh 2 double expression, 2-day-old embryos were treated with proteinase $\mathrm{K}(10 \mu \mathrm{g} / \mathrm{ml})$ for $20 \mathrm{~min}$ and fixed in $4 \%$ paraformaldehyde/PBS for $20 \mathrm{~min}$ at room temperature (RT). Subsequently, embryos were washed in PBT (PBS plus $0 \cdot 1 \%$ Tween 20 ) and incubated at $65{ }^{\circ} \mathrm{C}$ overnight with equal amounts of pth 2 and gnrh 2 probe in 50\% formamide buffer solution. After a series of washes, embryos were treated in blocking solution for $2 \mathrm{~h}$ at RT. Hybridization was detected by alkaline phosphatase-conjugated anti-DIG antibody and nitroblue tetrazolium chloride/5-bromo-4-chloro-3-indolyl phosphate (NBT/BCIP) following manufacturer's instructions (Roche Applied Science). Both the experimental and the control reactions were stopped at the same time by washing them with PBT.

\section{Results}

\section{Conserved syntenies for pth2}

Conserved syntenies provide evidence for the conservation of genome regions across evolutionary history. The conserved syntenies for pth2 (Fig. 1A) show that none of the human (Hsa) chromosomes that contain PTH paralogs (Hsa11, PTH; Hsa12, PTHLH; and Hsa19, PTH2, see Fig. 1F) had extensive conserved synteny with $D$. rerio linkage group 17 (Dre17), the location of pth2. Two genes immediately to the left and three immediately to the right of $p t h 2$ have orthologs widely separated on Hsa14, and as the dot plot shows, many other genes on Dre17 have orthologs on Hsa14, but Hsa14 has no PTH-related gene. Thus, human and zebrafish $p$ th 2 genes do not show conserved syntenies.

At least three hypotheses can account for these results. First, the location of the zebrafish gene may be incorrect due to an error in genome assembly. To test this possibility, we compared the position of pth 2 in zebrafish to that in the well-assembled genome of stickleback (Gasterosteus aculeatus, Gac). Results showed that genes near zebrafish pth2 had orthologs near stickleback pth2 (Fig. 1B). The agreement of these two genomes makes the incorrect-assembly mechanism unlikely. A second hypothesis is that chromosome rearrangements in the fish and/or tetrapod lineages destroyed any conserved synteny that might have originally existed. To test this mechanism, we compared human chromosome 19 (Hsa19), which contains PTH2, to the stickleback genome. Results showed that stickleback has two clear copies of most regions of Hsa19 (boxed in Fig. 1C), but that stickleback orthologs of the region around human PTH2 are distributed over several stickleback chromosomes, especially linkage groups II, V, VIII, XI, and XX (Fig. 1C). These results 
suggest that substantial chromosome rearrangements occurring in one or both lineages after the stickleback and human lineages diverged. Thirdly, zebrafish pth 2 may not be orthologous to human PTH2. To test this possibility, we constructed a maximum likelihood tree of the whole gene family. Results showed that zebrafish and pufferfish Pth2 clustered with human and mouse PTH2 (Fig. 1D). We conclude that pth 2 and PTH2 are orthologous genes.

Our searches of the chicken genomic and EST databases failed to identify a gene closely related to $P T H 2$, and this loss was confirmed by analysis of the zebra finch genome, suggesting that the $\mathrm{PTH} 2$ gene was lost in the bird lineage. To explore this point further, we searched Ensembl for chicken orthologs of genes neighboring PTH2 and discovered that nearly all neighbors within ten genes of PTH2 were missing from both chicken and zebra finch. In contrast, orthologs of most PTH2 neighbors - but not PTH2 itself were present in the anole lizard (Anolis carolinensis), which, like birds and crocodiles, is a diapsid, an animal with two temporal fenestra on each side of the skull (mammals are synapsids). To identify a mechanism for the loss of Pth 2 from the lizard-dinosaur-bird lineage, we compared human and lizard genome databases. Results showed that, like birds, lizard lacks PTH2 but has many nearby neighbors (Fig. 1E). A local inversion with a breakpoint between the two neighbors of the human PTH2 gene distinguishes the lizard and human regions. This result could happen if an inversion breakpoint destroyed PTH2 in diapsids. Further chromosome rearrangements may have contributed to the loss of additional neighboring genes from the bird lineage. We conclude that lizards and birds lack an ortholog of PTH2 due to a chromosome breakage event.

Finally, examination of paralogous chromosomes in the human genome show that PTH, PTH2, and PTHLH occupy paralogous chromosome segments in Hsa11, Hsa19, and Hsa12 respectively (Fig. 1F). These chromosome segments, along with a portion of Hsa1, most likely (see Dehal \& Boore 2005), are paralogous chromosome segments (paralogons) arising from the R1 and R2 rounds of early vertebrate genome duplication. We conclude that PTH, PTH2, and PTHLH are ohnologs arising in the R1 and R2 genome duplication events and that the fourth ohnolog went missing from bony vertebrates (Wolfe 2000, Postlethwait 2007).

\section{Expression of pth2}

We evaluated expression of pth 2 by whole-mount in situ hybridization and RT-PCR in various stages of development using $\beta$-actin as control: cleavage $(0 \cdot 75-2 \mathrm{~h}$ post-fertilization), blastula $(2 \cdot 25-4 \cdot 66 \mathrm{~h})$, segmentation $(10 \cdot 33-22 \mathrm{~h})$, and pharyngula $(24-42 \mathrm{~h})$ until the hatching period $(48-72 \mathrm{~h})$. Compared to control sense probe (no hybridization signal, data not shown), in situ hybridization using cRNA probes showed pth 2 transcript expression during cleavage $(1 \cdot 75 \mathrm{~h})$ and blastula stages (4 h; Fig. 2A-D). During segmentation $(19-22 \mathrm{~h})$, pth2 was expressed in forebrain, midbrain,

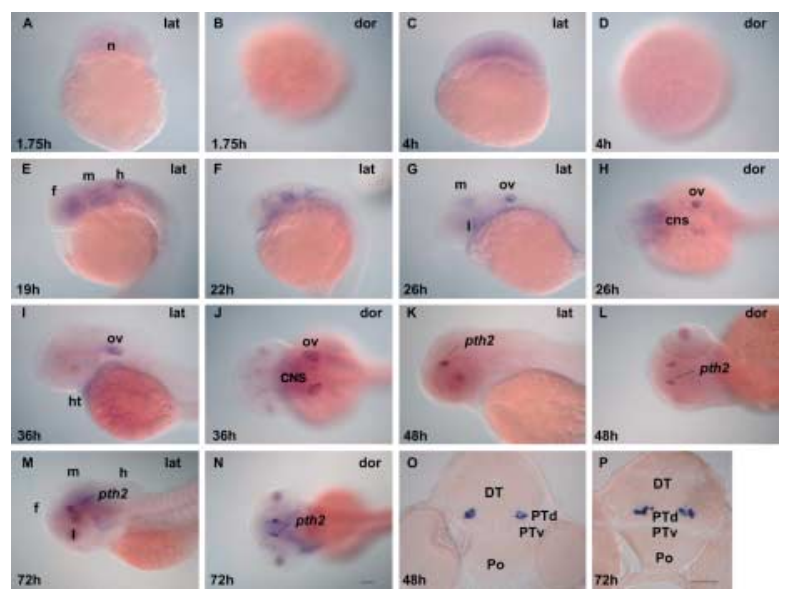

Figure 2 Developmental expression of zebrafish pth2 by wholemount in situ hybridization. (A-N) cleavage through hatching. $(\mathrm{O}$ and $\mathrm{P})$ Cross sections of $48 \mathrm{~h}(\mathrm{M})$ and $72 \mathrm{~h}(\mathrm{~N})$ embryos. CNS, central nervous system; $d$, dorsal; DT, dorsal thalamus; $f$, forebrain; h, hindbrain; I, lens; lat, lateral; m, midbrain; ov, otic vesicles; Po, preoptic region; PTd, dorsal part of posterior tuberculum; PTV, ventral part of posterior tuberculum, ap, animal pole. Scale bar is $50 \mu \mathrm{M}(\mathrm{A}-\mathrm{N}$ and $\mathrm{O}$ and $\mathrm{P})$. Images $\mathrm{O}$ and $\mathrm{P}$ are $2 \times$ the magnification of all other panels (A through $\mathrm{N}$ ).

hindbrain, and in cells lining brain ventricles (Fig. 2E and F). During the pharyngula stage $(26 \mathrm{~h})$, pth 2 transcript was observed in midbrain and otic vesicles (Fig. $2 \mathrm{G}$ and $\mathrm{H}$ ). Expression of $p$ th 2 in otic vesicles became more prominent at $36 \mathrm{~h}$ (Fig. 2I and J). In the hatching period (48-72 h), expression of pth 2 in brain became restricted to the paired domains near the forebrain-midbrain boundary that became more intense over time (Fig. $2 \mathrm{~K}-\mathrm{N}$ ). These paired domains lie adjacent to the ventral part of posterior tuberculum (Mueller \& Wullimann 2003). Bilateral pth2-expressing domains lie beneath dorsal thalamus anterior to preoptic region (Fig. $2 \mathrm{O}$ and $\mathrm{P}$ ). Zebrafish gnrh 2 has been reported to be expressed near the pth 2 domains we describe here (Gopinath et al. 2004, Kuo et al. 2005). To evaluate how the expression of pth 2 and gnrh 2 are close to each other spatially, we double-labeled zebrafish embryos for pth 2 and gnrh2 expression. Double labels showed that the pth2 expression domain was anterio-ventral to gnrh2-expressing cells (Supplementary Figure 2, see section on supplementary data given at the end of this article). Thus, pth2 and gnrh2 transcripts are expressed in two distinct but nearby paired domains. RT-PCR supports the conclusion from the wholemount in situ study that pth 2 mRNA was present at all stages tested (Supplementary Figure 3, see section on supplementary data given at the end of this article). We conclude that $p$ th 2 transcript is present in embryos long before the midblastula transition, the stage at which zygotic genes are first expressed and thus pth 2 is expressed very early in zygotes (mRNA that is synthesized during oogenesis and deposited in the cytoplasm of the cells in the egg). 
Factors that regulate the development of PTH2-expressing cells have been incompletely investigated. Because shha and pth2 are expressed within several cell diameters of each other (Papasani et al. 2004), we hypothesized that hedgehog signaling might direct the development of pth2-expressing cells, consistent with the regulation of nk2.2-expressing cells several cell diameters distant from shh-expressing cells (Barth \& Wilson 1995). To test this hypothesis, we evaluated expression of pth2 and gnrh2 (a gene expressed by the hypothalamus) in animals lacking either shha activity (syu; sonic-you mutants (Schauerte et al. 1998) or all hedgehog signaling (smo; slow-muscle-omitted mutants (Varga et al. 2001)). Compared to wild types (Fig. 3A and B), syu mutant embryos had fewer cells expressing pth 2 and fewer cells expressing gnrh2 (Fig. 3C and D). This result shows that shh signaling is essential for the development of $p$ th 2 and gnrh 2 expression but is not required for the specification of at least some pth2- and gnrh2-expressing cells. In contrast, removal of all hedgehog signaling by mutation of smo, which encodes the receptor for Shh and other hedgehog proteins (Varga et al. 2001), dramatically reduced the development of pth2 transcript expression but merely diminished the number of gnrh2 transcript expression (Fig. 3E and F).
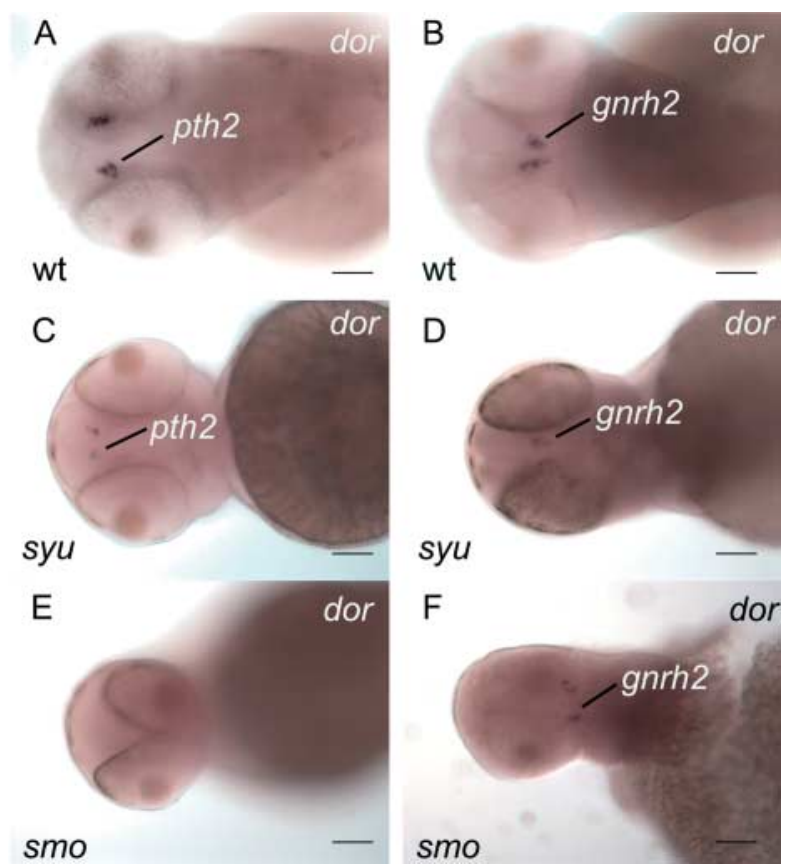

Figure 3 pth2 and gnrh2 expression in syu mutants. To investigate the regulation of pth2-expression by Shha, we performed wholemount in situ hybridization for pth2 and gnrh2 on wild-type (wt), smo and syu mutant embryos at $48 \mathrm{~h}$. Results showed decreased expression of both the pth2 (C) and gnrh2 (D) in syu mutants in comparison to wild types (A, B). In contrast, smo mutants only showed a small decrease in gnrh2-expression $(F)$ with the total loss of pth2 expression (E). These experiments show that shha signaling is important for the normal development of pth2 and gnrh2 transcript expression. Scale bar is $50 \mu \mathrm{M}$.
Because Pth2 can regulate the hypothalamo-pituitary axis in rats (Ward et al. 2001, Wang et al. 2002), we performed single- and double-label experiments to examine pth2- and gh1-expressing cells (Herzog et al. 2003). Results showed that gh1-expressing cells of the anterior pituitary (Supplementary Figure $4 \mathrm{C}$ and D, see section on supplementary data given at the end of this article) occupied a single medial cell group located ventral and posterior to the paired pth2 domains (Supplementary Figure 4A, B, E and F, see section on supplementary data given at the end of this article). We conclude that if Pth2 regulates Gh1 secretion in zebrafish, as suggested in rat, then it likely does so indirectly, possibly by regulating the hypothalamo-pituitary axis. Further studies are necessary to fully understand the mechanism.

The pth 2 gene was expressed not only in the CNS and in the developing otic vesicles but also in the zebrafish heart (Papasani et al. 2004). To better understand the role of pth 2 in the developing heart, we marked various chambers using myosin light polypeptide 7 ( $m y l 7$, alias $c m l c 2)$, which is expressed throughout the ventricular and atrial portions of the heart tube (Supplementary Figure 5C and D, see section on supplementary data given at the end of this article) and ventricle-specific myosin heavy chain gene vmhc (Supplementary Figure 5E and F, see section on supplementary data given at the end of this article; Yelon 2001). We observed diffuse expression of $p$ th 2 throughout the atrial and ventricular regions of the developing heart tube at $48 \mathrm{~h}$ (Supplementary Figure 5A and B, see section on supplementary data given at the end of this article). We conclude that pth 2 expression is not confined to a single portion of the heart tube at the stages examined.

\section{Genomic structure of $\mathrm{pth} 2 \mathrm{r}$}

The Pth2 ligand acts by binding and activating the Pth2r (John et al. 2002, Papasani et al. 2004). To understand the evolutionary origin and biological roles of Pth2r in zebrafish, we first studied its genomic structure. We used BLAST searches of the Ensembl zebrafish Zv8 genomic database (Rubin et al. 1999; http://pre.ensembl.org/ Danio_rerio/) to identify contigs with sequence identity to our pth2r cDNA (NM_131377). Contig CU459122.18 contains exons EL2, M5, M6/7 and M7, and T along with the corresponding introns (Fig. 4A); contig BX001055.11 contains exons S, E1, E3, G, M1, M2, M3, and M4; and contig CU862080.5_01118 contains exons M4, EL2, M5, and M6/7.

The organization of $p$ th $2 r$ was deduced from our cDNA (Rubin et al. 1999) and by designing pth $2 r$ exonic primers to determine intron-exon borders and intron lengths on genomic DNA. Our deduced $p$ th $2 r$ gene consists of 15 exons (including the splice variant SV\#19 and exon U, Fig. 4A). By comparing cDNA to gDNA, we validated the intron-exon borders of the 15 exons (from exon $\mathrm{S}$ through $\mathrm{T}$ ) and sizes of many introns. A comparison of zebrafish pth $2 r$ to human PTH2R (transcript ID ENST00000413482; Fig. 4A) showed 
A
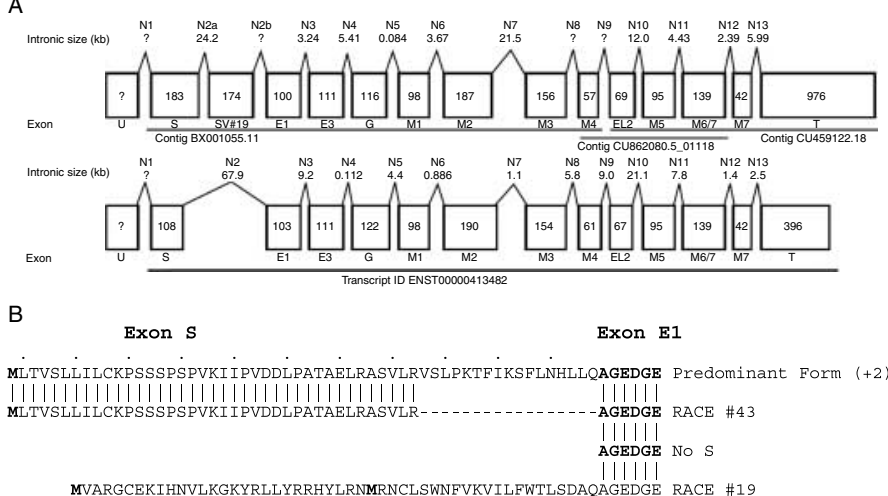

C

Exon $S$ for pth2r gDNA

aggectcaccatctttgtctctaaccaatgacaaacatctc IC ITTTTTGATCTTCAGGATG CTGACGGTGTCATTATTGATCCTCTGCAAGCCTTCTTCCTCTCCCTCACCTGTAAAGATT ATACCTGTGGATGACCTTCCGGCCACTGCTGAGCTACGGGCTTCTGTTCTCCGCgtCAGT CTGCCAAAGACATTTATCAAGTCATTTCTCAATCATCTGCTTCAAGCDagtatcacgaac

Figure 4 Consensus structure of the genomic sequence encoding the zebrafish pth2r and $5^{\prime}$-splice variants. (A) Zebrafish pth2r genomic structure (top panel) compared with human PTH2R (transcript ID ENST00000413482, bottom panel). Boxes show exon sizes in base pairs (bp) with their identifications directly below. The intronic sequences (N1, N2a, N2b, .. N13) with respective sizes are indicated between their flanking exonic boxes. N? indicates an intron of unknown size. Bars indicate contigs containing the respective exons. (B) Multiple and independent 5'-RACE experiments using adult total zebrafish RNA produced four different amplicons encoding exon S. Amino acids were aligned at exon $\mathrm{E} 1$ (in bold) and subsequently aligned and extended $5^{\prime}$ (exon S). In addition to the predominant amplicon (predominant pth2r) and pth2r(43) (shorter by 17 residues than the predominant pth2r, Rubin \& Jüppner 1999a,b, Rubin et al. 1999, Hoare et al. 2000, Papasani et al. 2004), we identified two additional transcripts that indicated alternate splicing (Joun et al. 1997). (C) The nucleotide sequence of $p t h 2 r$ genomic DNA encoding exon S for both the predominant pth2r and pth2r(43) and (D) a novel signal peptide arising from exon SV \#19 respectively. The pth2r-SV \#19 transcript has a conserved intron donor (ID) and intron acceptor (IC) recognition sequence. The initial methionine ATG is bold and underlined. Coding nucleotides are in uppercase and untranslated introns are in lowercase font. Splice donor and acceptor sites are in boxes.

that human PTH2R has 14 exons (from exon U through T) similar to that of zebrafish $p t h 2 r$ (excluding the splice variant SV\#19).

\section{pth2r splice variants}

We previously isolated two $p t h 2 r$ transcripts, one of $2429 \mathrm{bp}$ (which we call pth2r-predominant form) and one with a $5^{\prime}$-splice variant pth2r(43) of 2378 bp that lacked 17 amino acids in the amino-terminal extracellular domain (Rubin et al. 1999). In studies reported here, we confirmed the original two forms, pth2r-predominant and the $5^{\prime}$-splice variant pth2r(43), but further identified two additional splice variants by multiple and independent $5^{\prime}$-RACE experiments using adult zebrafish total RNA with pth $2 r$-specific primers. The first new $p t h 2 r$ splice variant lacked exon $\mathrm{S}$ and began at exon E1 (pth2r - No-S, Fig. 4B). The second new pth $2 r$ splice variant is pth2r-SV\#19 and is encoded by a novel signal peptide SV\#19 (accession number GU002363; Fig. 4B). A search of the zebrafish genome at Ensembl identified significant sequence identity corresponding to the pth2rSV\#19 cDNA sequence on contig BX001055.11.

To define exons encoding our $5^{\prime}$-RACE products (predominant-pth2r, pth2r(43), pth2r No S, and pth2rSV\#19), we compared structures to $p t h 2 r$ gDNA. We found that exon $\mathrm{S}$ for $p t h 2 r$ gDNA has an intron acceptor site (agTT) that is 14 nucleotides $5^{\prime}$ to the initiator ATG, which is found in both the predominant pth2r form and in pth2r(43) (Fig. 4C). In the predominant pth2r form, an intron donor site (AGca) is 164 nucleotides $3^{\prime}$ to the initiator ATG, while an intron donor site (GCgt) observed in pth2r(43) is 112 nucleotides $3^{\prime}$ of the ATG (Fig. 4C). Thus, pth2r(43) is shorter than predominant pth2r at the $3^{\prime}$-end while the rest of the nucleotides remain constant in exon $\mathrm{S}$ for both of them. The newly discovered pth2r-SV\#19 transcript has consensus intron donor and acceptor sites (AGgt and agAT respectively; Fig. 4D). The novel splice variant pth2r-SV\#19 we found here either lacks a mammalian equivalent or its mammalian equivalent is yet to be identified.

\section{Phylogenetic analysis of $\mathrm{Pthr}$ genes}

To help understand the relationships and histories of vertebrate Pthr genes, we conducted a phylogenetic analysis (Fig. 5A). Results confirmed that vertebrates have three Pthr genes (Rubin et al. 1999). Pth1r is present in tetrapods, birds, an amphibian, and teleosts, and tree topology matches accepted species relationships (Fig. 5A). The zebrafish pth $2 r$ gene (Rubin et al. 1999) falls in the PTH2R clade with strong bootstrap support along with the pth $2 r$ of other teleosts (Fig. 5A). Furthermore, while mammals and an amphibian have a clear $P T H 2 R$ ortholog, reciprocal best amino acid identity matches by basic local alignment search tool (BLAST; Altschul et al. 1997) searches of two sequenced bird genomes (chicken and zebra finch) failed to identify any Pth2rortholog. This suggests that Pth $2 r$ was present in the last common ancestor of all vertebrates but was lost from the bird lineage after it diverged from the mammalian lineage. Reciprocal best BLAST analyses revealed a single clear ortholog of PTH3R in the genomes of two birds, an amphibian, and several teleosts 

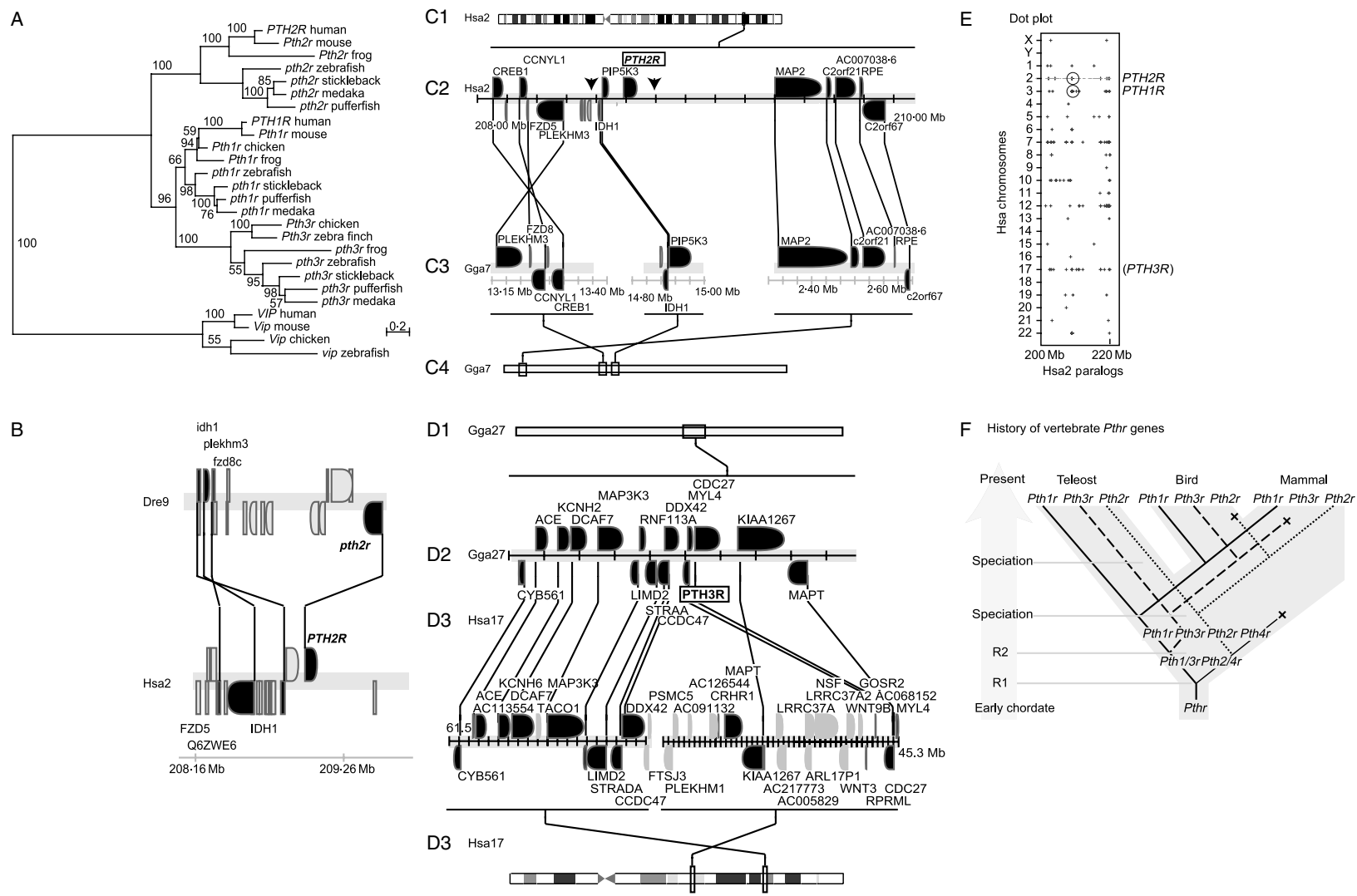

Figure 5 Phylogenetic and conserved synteny analysis for PTH receptors. (A) Maximum likelihood tree of Pthr amino acid sequences rooted on the related sequences of VIP. Numbers on branches are bootstrap values of 100 iterations. Results show that teleost $p$ th $2 r$ genes are orthologs of human PTH2R; that Pth 1 r is present in teleosts, birds, and mammals and that Pth3r is present in teleosts, an amphibian, and birds but is missing from mammals. (B) Conserved syntenies of human and zebrafish $P T H 2 R$ and pth2r genes. The portion of zebrafish chromosome Dre9 containing pth2r shows conserved syntenies with human chromosome 2 (Hsa2) near PTH2R. Lines connect orthologs between zebrafish and human. (C). Conserved syntenies suggest a mechanism for the loss of Pth2 $r$ from the avian lineage. $\mathrm{C} 1$, idiogram of human chromosome 2 (from Ensembl); C2, expansion of the region boxed in part C1, showing genes transcribed left to right on the top, and in the reverse orientation on the bottom; $\mathrm{C} 3$, the three regions of chicken chromosome 7 (Gga7) that are orthologous to the human chromosome segment containing PTH2R; C4, chicken chromosome 7 with the regions shown in detail in part C marked with boxes. The human PTH2R gene lies near chromosome transposition breakpoints (arrowheads). (D) Conserved syntenies suggest a mechanism for the loss of Pth3r from the human lineage. D1 and chicken chromosome 27 with the boxed area blown up in D2. D3, two portions of human chromosome 17 that contain the chicken orthologs of the region surrounding Pth3r; D4, the position of the two human chromosome segments on Hsa17 that are orthologous to the single region centered on Pth $3 r$ in the chicken genome. (E) A dot plot showing paralogs of genes surrounding PTH2R on Hsa2. The location of PTH2R and its paralog PTH1R are marked by circles and the presumed location of the missing PTH3R gene on Hsa17 is indicated in parentheses. (F) A history of the Pthr family. The most parsimonious explanation from evidence from phylogenetic and conserved synteny analysis is that Pth $1 r$ (solid line), Pth $2 r$ (dotted line), and Pth $3 r$ (dashed line) arose in the R1 and R2 rounds of vertebrate genome duplication and that the fourth expected gene, Pth4r (thin line) was lost shortly thereafter (X). After the speciation event separating teleost and tetrapod lineages, both lineages initially had genes for Pth1r, Pth2r, and Pth3r, but after the speciation event separating bird and mammalian lineages, Pth $3 r$ was lost in the mammalian lineage and Pth $2 r$ was lost in the bird lineage $\left(X^{\prime} s\right)$. The investigation of gene functions in this gene family has the potential to show how ancestral gene functions evolve and partition after gene duplication and lineage-specific gene loss. Abbreviations and accession numbers: human genes and their (chicken orthologs): AC007038.6 (ENSGALG00000002828), C2orf21 (C2orf21), C2orf67 (C2orf67), CCNYL1 (ENSGALG00000008485), CREB1 (NP 989781), FZD5 (FZD8), IDH1 (IDH1), MAP2 (MAP2), PIP5K3 (PIP5K3), PLEKHM3 (PLEKHM3), RPE (RPE). PTH1R zebrafish, NP571432; PTH2R zebrafish, NP571452; PTH3R zebrafish, NP571453; VIP zebrafish, NP001013371; PTH1R stickleback (Gasterosteus aculeatus), ENSGACG00000017402; PTH2R stickleback, ENSGACG00000007845; PTH3R stickleback, ENSGACG00000007096; PTH1R stickleback, XP418507; PTH1R chicken, DQ914925; PTH3R chicken, XP425837 (EU250015); VIP chicken, XP418492; PTH1R human, NP000307; PTH2R human, NP005039; VIP human, NP004615; PTH1R mouse, NP035329; PTH2R mouse, NP644676; VIP mouse, BAA81896; PTH1R medaka (Oryzias lapides), ENSORLG00000017615; PTH2R medaka, ENSORLG00000018121; PTH3R medaka, ENSORLG00000005645; PTH3R zebra finch (Taeniopygia guttata), ENSTGUG00000001924; PTH1R pufferfish (Tetraodon nigroviridis), CAF98426; PTH2Ra pufferfish, CAF97204; PTH3R pufferfish, CAG12650; PTH1R frog, (Xenopus tropicalis), ENSXETG00000003683; PTH2R frog, ENSXETG00000008019; PTH3R frog, ENSXETG00000003243. 
(Fig. 5A), but none in mammalian genomes. We conclude that the Pth $3 r$ gene was present in the last common ancestor of all vertebrates but was lost from mammalian genomes after they diverged from bird genomes. Thus, the ancestral functions of the Pthr gene family must be partitioned differently in mammals and other vertebrates (Fig. 5F).

\section{Zebrafish $\mathrm{pth} 2 \mathrm{r}$ shares conserved syntenies with human $\mathrm{PTH} 2 \mathrm{R}$}

The hypothesis that zebrafish $p t h 2 r$ is an ortholog of human PTH2R predicts that the two genes should reside in orthologous chromosome segments. To test this property, we investigated conserved syntenies using the Synteny Database (Catchen et al. 2009). Results showed that zebrafish $p t h 2 r$ has neighbors that have human orthologs residing near PTH2R on human chromosome 2 (Hsa2; Fig. 5B). We conclude that $p t h 2 r$ has conserved synteny with the human genome, consistent with orthology.

To investigate the genomic basis for the loss of Pth $2 r$ from birds, we compared human and chicken genomes (Fig. 5C). Results showed that the $2 \mathrm{Mb}$ segment orthologous to the human PTH2R neighborhood (Fig. 5C1 and 2) extends over three different regions of chicken chromosome 7 (Fig. 5C3 and 4). The close linkage of Pth $2 r$ with Idh1, Plekhm3, and Fzd8 is shared by human and zebrafish and is hence ancestral (Fig. 5B), but these regions are widely separated on chicken chromosome 7. The parsimonious explanation is that a transposition event disturbed the region between PIP5K3 and MAP2 in the avian lineage and that this breakage event may have led to the loss of the avian Pth2r gene.
Reciprocally, Pth $3 r$ was lost from the mammalian genome (Fig. 5A). In chicken, Pth $3 r$ is located between $M Y l 4$ and Ddx42 (Fig. 5D1 and 2), but the human orthologs of MYL4 and DDX42 are located far apart on Hsa17 (Fig. 5D3). This arrangement would be predicted if a chromosome transposition/inversion event disrupted the Pth $3 r$ gene in a mammalian ancestor and separated genes that were ancestral neighbors.

Two rounds of whole genome duplication occurred in an ancestor to all extant vertebrates (Garcia-Fernandez \& Holland 1994, Holland et al. 1994, Spring 1997, Dehal \& Boore 2005). We wondered whether the PTHR gene family originated in these events. We used the Synteny Database (Catchen et al. 2009) to examine the distribution of human paralogs surrounding PTH2R (Fig. 5E). Results showed that Hsa2, 3, 7, 10, 12, and 17 had large numbers of paralogs of Hsa2 genes. Coupled with the conserved synteny analysis of Fig. 5D, the results suggest that PTH3R 'should have' been located on Hsa17 if it had not gone missing (Fig. 5F).

\section{Expression of pth2r}

To compare gene expression patterns of Pth2 and its receptor Pth2r, we evaluated pth2r (pth2r-predominant form) distribution in space and time by whole-mount in situ hybridization and its expression by RT-PCR. Compared to control sense probe (no hybridization signal, data not shown), in situ hybridization using cRNA probes showed pth2r transcript during cleavage before the mid-blastula transition $(1 \cdot 75-2 \mathrm{~h})$, indicating that $p$ th $2 r$ is very early expressed (Fig. 6A-D). Nuclei at $2 \mathrm{~h}$ appeared to have accumulated $p t h 2 r$ transcript
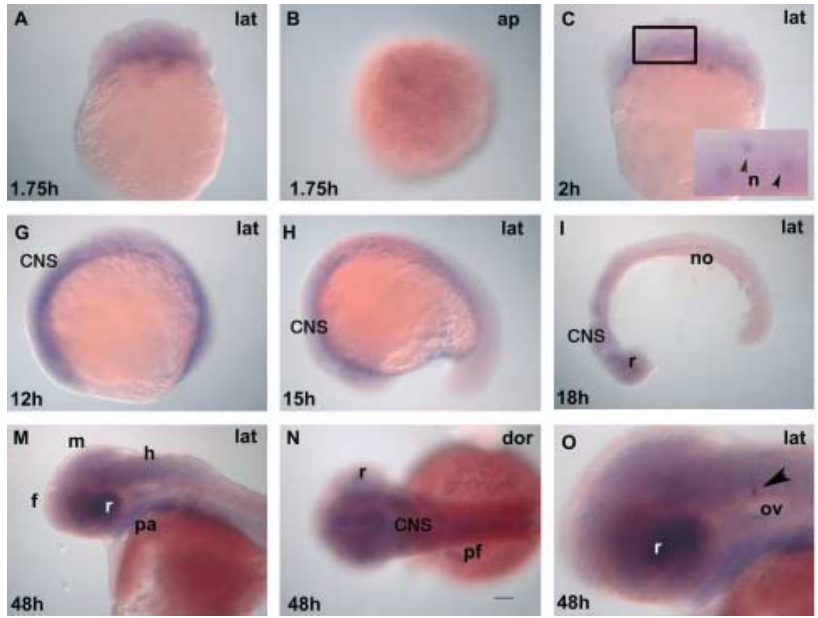

$48 \mathrm{~h}$
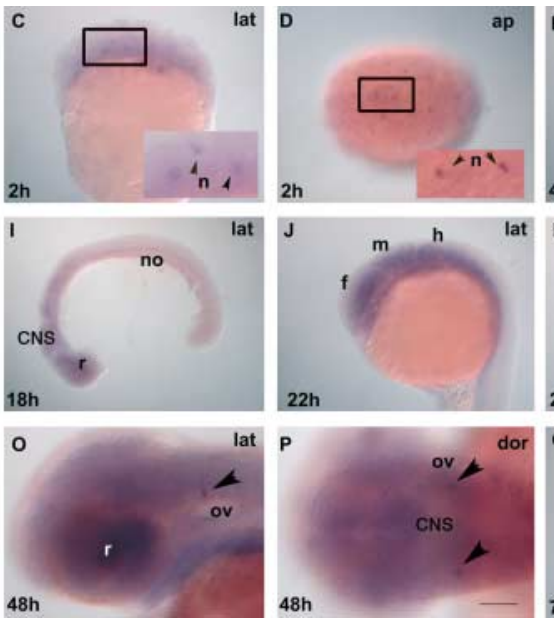
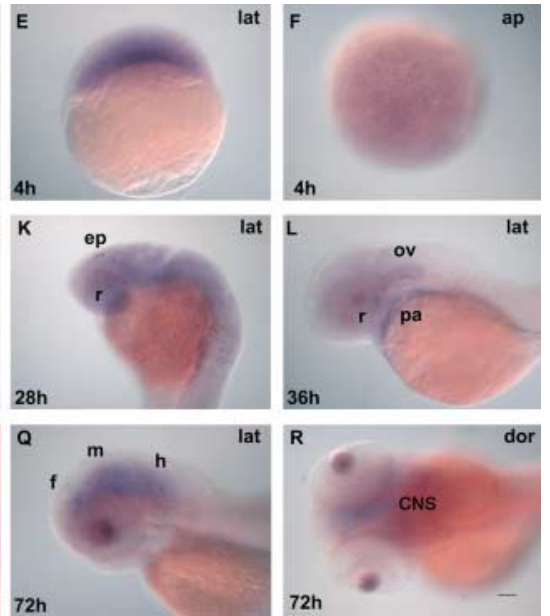

Figure 6 Developmental expression of zebrafish pth2r (pth2r predominant form). Tissue-specific expression of zebrafish pth2 $r$ mRNA by whole-mount in situ hybridization using pth2r probe. Lateral (lat) and dorsal (dor) images of pth2r expression from cleavage through hatching periods (A-P) showed the expression of pth2r transcript in central nervous system (CNS), epiphysis (ep), forebrain (f), hindbrain (h), midbrain $(\mathrm{m})$, otic vesicle (ov), nucleus, blown up and indicated with arrowhead (n), notochord (no), pharyngeal arches (pa), pectoral fin (pf), and retina (r). $\mathrm{O}$ and $\mathrm{P}$ are the higher magnification view of the preparation shown in $\mathrm{M}$ and $\mathrm{N}$ confirming that pth2r-expressing cells are in the developing otic vesicles (indicated with arrowhead). ap indicates animal pole. Scale bar is $50 \mu \mathrm{M}(\mathrm{A}-\mathrm{N}, \mathrm{O}-\mathrm{P}$, and Q-R). Images O and P are $2 \times$ the magnification of all other panels. 
(Fig. 6C and D, enlarged and cell-specific nuclei are indicated with arrowhead) and many cells in the blastula $(4 \mathrm{~h})$ showed pth $2 r$ expression (Fig. 6E and F). During early segmentation at $12 \mathrm{~h}$, pth $2 r$ transcript was expressed throughout the developing CNS (Fig. 6G), and at 15 and $18 \mathrm{~h}$, pth $2 r$ transcript accumulated in brain, eye, and notocord (Fig. $6 \mathrm{H}$ and I). At $22 \mathrm{~h}$, pth $2 \mathrm{r}$ was expressed in forebrain, midbrain, and hindbrain (Fig. 6J). At $28 \mathrm{~h}$, we found strong expression in the epiphysis (Fig. 6K). At $36 \mathrm{~h}$, we observed prominent expression in the otic vesicles and pharyngeal arches (Fig. 6L). At $48 \mathrm{~h}$, pth $2 r$ was robustly expressed in the forebrain, midbrain, hindbrain, retina, and pharyngeal arches (Fig. 6M and $\mathrm{N}$ ) and also in the otic vesicles (Fig. $6 \mathrm{O}$ and P). At $72 \mathrm{~h}$, $p t h 2 r$ expression became more restricted to the midbrainhindbrain region (Fig. 6Q and R). RT-PCR experiments supported the whole-mount in situ study that pth $2 r$ mRNA was present at all stages tested, suggesting early onset and continued presence of the transcript (Supplementary Figure 1).

These results show that $p t h 2 r$ is widely and robustly expressed throughout the CNS in a pattern much broader than pth 2 at the same stages. The very early onset of ligand and receptor expression suggests their involvement in early development. Ligand (Fig. 2E) and receptor (Fig. 6J) genes were both expressed in the forebrain, midbrain, and hindbrain in segmentation stages, but later, expression of the ligand became more restricted. Although we detected expression of the receptor in the retina (Fig. 6I, K, L and M), we did not detect it in the heart where the ligand gene was expressed. We also observed the expression of the receptor gene in the otic vesicles; we found that the ligand and receptor are both expressed in otic vesicles, but the highest concentration of ligand expression (Fig. 2G-J) is not at the same location as that of receptor (Fig. 6L, O and P). Nevertheless, the expression of $p t h 2$ and $p t h 2 r$ mRNA in the ear at the same time suggests a role in otic development, although further functional studies are required to confirm this proposed interaction.

\section{Discussion}

\section{Different vertebrates have different subsets of $\mathrm{PTH}$ ohnologs}

Our analysis of paralogons in the human genome show that PTH, PTH2, and PTHLH are ohnologs, paralogs derived from the R1 and R2 rounds of whole genome duplication that occurred at the base of the vertebrate radiation (Dehal \& Boore 2005). Zebrafish pth2 and human PTH2 are highly likely to be orthologous genes (Papasani et al. 2004) despite the lack of conserved syntenies, which probably happened by chromosome arrangements that stirred the PTH2 or pth2 neighborhoods with respect to each other in 450 million years since the last common ancestor of human and zebrafish and thereby abolished any evidence of conserved synteny. Examination of bird and lizard genomes showed that the diaspid lineage lacks an ortholog of PTH2, which was neatly deleted from the lizard genome and which was part of a larger chromosome segment that is deleted in the bird genome. The significance of this finding is that birds and lizards perform the combined roles of PTH, PTH2, and PTHLH solely by the use of PTH and PTHLH. Whether birds and lizards apportion the mammalian roles of $P$ TH2 between their PTH and PTHLH genes or whether they lack the genespecific roles of $P T H 2$ is a question for future research. In any event, this finding has significance because it means that different lineages of vertebrates have different PTH family genes and hence variations in PTH family gene functions.

\section{Zebrafish pth2 has overlapping expression patterns with the mammalian PTH2 gene}

Expression studies showed that in zebrafish, pth2 was expressed at very early stages of development and then showed widespread expression in zygotes that gradually become constrained to the heart and otic vesicles and to the forebrain-midbrain boundary close to gnrh2-expressing cells, suggesting roles in early brain (Blind et al. 2003, Wortmann et al. 2003) and heart development (Yelon 2001, Yelon et al. 2002, Dobolyi et al. 2003a,b).

Factors that regulate the development of PTH2-expressing cells have been incompletely investigated. Our results show that knockdown of hedgehog signaling substantially reduces the number of cells expressing pth2 but has less effect on the number of cells expressing gnrh2. Knockdown of all hedgehog signaling by mutation of the receptor was more severe than removal of Shha alone, suggesting that the expression of Indian hedgehog genes (ihha and $i h h b$ ), which are expressed in the branchial arches (Avaron et al. 2006) or less likely shhb (Ekker et al. 1995), may influence the development of pth2-expressing cells. We further conclude that the development of pth2-expressing cells is more sensitive to hedgehog signaling than is the development of gnrh2-expressing cells. These results are consistent with the finding that Hh signaling regulates development of the diencephalon and hypothalamus (Mathieu et al. 2002, Scholpp et al. 2006). Because desert hedgehog $(d h h)$ is not expressed in zebrafish until $\sim 6 \mathrm{dpf}$ (Avaron et al. 2006), it is unlikely to be involved in signaling relevant to pth2-expressing cells. Previous studies showed that i.c.v. administration of Pth 2 in rat brain increases $\mathrm{GH}$ releasing factor and decreases pulsatility of GH release; thus, Pth2 can control the hypothalamo-pituitary axis (Ward et al. 2001, Wang et al. 2002). Our Pth2 and Gh1 expression study suggests that if Pth2 regulates Gh1 secretion in zebrafish as it does in rats, then control is likely indirect by regulation of the hypothalamo-pituitary axis.

Comparison of Pth2 expression among various vertebrates provides clues to the evolution of its developmental roles. Pth2-positive neurons are widely expressed in two distinct brain regions in both mice and rats (Dobolyi et al. 2003a, Faber et al. 2007), including the subparafascicular area (Wang et al. 2006) and the medial paralemniscal nucleus at the midbrain-pons junction (Varga et al. 2008). PTH2-expressing 
neurons were also present in the subparafasicular area and in the medial paralemniscal nucleus in 3-day-old male macaque brain (Bago et al. 2009). PTH2 mRNA was found abundantly in the human CNS, trachea, fetal liver, and, to a lesser degree, in human heart and kidney (Hansen et al. 2002). We observed zebrafish pth2 expressed adjacent to the ventral posterior tuberculum at $48 \mathrm{~h}$ and throughout the CNS at younger stages. Thus, pth 2 is expressed in overlapping subsets of brain regions in zebrafish, rodents, and humans. We conclude that the Pth2 expression domain in the ventral forebrain plays an ancient phylogenetically conserved role in vertebrate development or physiological function.

Zebrafish and mammals share additional pth2 expression domains. As in zebrafish, the human heart and rat aorta express Pth2 (Eichinger et al. 2002, Hansen et al. 2002). We also observed pth $2 \mathrm{mRNA}$ in zebrafish otic vesicles at $48 \mathrm{~h}$, consistent with the hypothesis that pth 2 is involved in otic vesicle development or auditory functioning (Dobolyi et al. 2003a). The correspondence of gene expression patterns suggests that $P T H 2$ has specific broadly shared developmental and/or physiological roles in the brain, heart, and otic vesicles among different species and thus reflects ancestral functions present at least at the origin of bony fishes 450 million years ago.

\section{pth2r gene structure}

Comparative genomics of the zebrafish pth $2 r$ and the human $P T H 2 R$ genes showed similar exon structure but identified two novel splice variants. The zebrafish splice variant that lacked exon $\mathrm{S}$ and starts with exon E1 is likely nonfunctional like the corresponding human PTH1R transcript (Joun et al. 1997). For the splice variant pth2r-SV\#19, residues located downstream of the signal peptide are in-frame and code for the predominant pth2r transcript previously described (Rubin et al. 1999). Phylogenetic and conserved synteny analysis showed that Pth2r was lost from the bird lineage after it diverged from the mammalian lineage and that $P t h 3 r$ was lost from mammalian genomes after they diverged from bird genomes. Our analysis supports the conclusion that the last common ancestor of teleosts and tetrapods had three Pthr genes, probably arising in two rounds of whole genome duplication in a stem vertebrate (R1 and R2) and that Pth $3 r$ went missing in the mammalian lineage after it diverged from the bird lineage, while Pth $2 r$ was deleted from the bird lineage after it diverged from the mammalian lineage. Because no extant organisms have been shown to have a fourth $p t h r$, we conclude that $p t h 4 r$ was lost shortly after $2 \mathrm{R}$, consistent with the finding that loss of a paralog after gene duplication is the most common fate of a pair of gene duplicates (Haldane 1933, Nei \& Roychoudhury 1973, Bailey et al. 1978, Watterson 1983). Our genomic analysis shows that, as with paralogs for PTH gene family ligands, paralogs for the PTHR receptors are different in different classes of vertebrates. The important implication, again, is that different lineages of vertebrates may accomplish different functions with these different gene sets, or that, in toto, they accomplish the same functions but that these functions are spread out over different individual genes.

Analysis of zebrafish $p$ th $2 r$ expression patterns revealed a pattern generally similar to that previously reported in mouse and primate brains in the hypothalamus, cerebellum, and cerebral cortex (Faber et al. 2007, Bago et al. 2009). Pth2r has also been detected throughout the cardiovascular system, including vascular endothelium and smooth muscle of rat (Usdin et al. 1999a), but we were unable to detect pth2r expression in the zebrafish embryonic heart. Additionally, we detected $p t h 2 r$ in the ear in a different location to that of $p t h 2$, which is nevertheless consistent with the action of a diffusible ligand. In situ hybridization experiments, of course, do not detect protein; thus to address whether Pth2 is transported necessitates the use of a Pth2 antibody.

\section{Conclusions}

This study revealed genomic and functional similarities and differences among vertebrate lineages for the PTH2-PTH2R ligand-receptor system. We identified an additional and novel signal peptide pth2r-SV\#19. The identification of additional signal exons may facilitate future studies on the number and location of promoters for PTH2R. We also established that both the ligand and the receptor are expressed in otic vesicles and are thus positioned to be involved in auditory development. Moreover, the expression of the ligand throughout the heart suggests its possible involvement in heart development. Future knockout studies are essential to test these hypotheses. Additionally, we found that hedgehog signaling regulates the development of Pth2 ligand-producing cells but has less effect on gnrh2-expressing cells. This information provides a foundation essential for future functional analyses of this ligand-receptor complex in zebrafish.

Of broader importance, our conserved synteny and phylogenetic studies showed that the three vertebrate $P T H$ family and PTHR family genes likely arose in two rounds of whole genome duplication at the base of the vertebrate radiation; that the PTH2 ligand is present in mammals and fish but absent from the sequenced genomes of lizards and birds; and that the PTH2R receptor is absent from birds, reciprocally, that the $P T H 3 R$ receptor is absent from mammals, and finally that zebrafish has copies of all three genes. We conclude that the variation in gene content across vertebrate classes provides ample leeway for variations in functions of the genes that constitute this ligand-receptor system in each vertebrate lineage. The variation among animal genomes shown here is particularly important in two cases; first, when suggesting functions for a human gene of medical importance from investigations on a teleost fish or bird model, we must be certain we are comparing orthologs. Secondly, when trying to infer the evolutionary origin of endocrine systems, such as the parathyroid gland, if we do not compare orthlogous genes from different taxa, then we may 
make inappropriate inferences. Thus, our data provide a foundation for further investigation of the biological roles of the Pth2-Pth2r complex.

\section{Supplementary data}

This is linked to the online version of the paper at http://dx.doi.org/10.1530/ JOE-00-0439.

\section{Declaration of interest}

The authors declare that there is no conflict of interest that could be perceived as prejudicing the impartiality of the research reported.

\section{Funding}

We thank grant sponsors: National Center for Research Resources (NCRR) grant number 3R01RR020833 (J P), National Institute of Child Health and Human Development grant numbers P01 HD22486 (J P), and HD05034 (D A R), and National Institute of Diabetes and Digestive and Kidney Disease grant number DK60513 (D A R). The contents of the paper are solely the responsibility of the authors and do not necessarily represent the official views of grant sponsors.

\section{Author contribution statement}

All authors contributed in the research design; P B and Y L Y performed research; all authors contributed in the data analyses; and all authors contributed in the writing of the manuscript.

\section{Acknowledgements}

This work was covered by Animal Welfare Assurance Numbers A-3009-01 (JP) and A-3762-01 (DAR), IACUC protocols 14-2002 (DAR) and 05-15 RRAA (JP), 06-09 RRAA (JP), and Biosafety IBC protocols 11B-2003 and 02B-2008 (DAR).

\section{References}

Altschul S, Madden T, Schaffer A, Zhang J, Zhang Z, Miller W \& Lipman D 1997 Gapped BLAST and PSI-BLAST: a new generation of protein database search programs. Nucleic Acids Research 25 3389-3402. (doi:10. 1093/nar/25.17.3389)

Amores A, Suzuki T, Yan YL, Poleroy J, Singer A, Amemiya C \& Postlethwait J 2004 Developmental roles of pufferfish Hox clusters and genome evolution in ray-finned fish. Genome Research 14 1-10. (doi:10.1101/gr.1717804)

Avaron F, Hoffman L, Guay D \& Akimenko M 2006 Characterization of two new zebrafish members of the hedgehog family: atypical expression of a zebrafish indian hedgehog gene in skeletal elements of both endochondral and dermal origins. Developmental Dynamics 235 478-489. (doi:10.1002/ dvdy.20619)

Bago A, Dimitrov E, Saunders R, Seress L, Palkovits M, Usdin T \& Dobolyi A 2009 Parathyroid hormone 2 receptor and its endogenous ligand tuberoinfundibular peptide of 39 residues are concentrated in endocrine, viscerosensory and auditory brain regions in Macaque and human. Neuroscience 162 128-147. (doi:10.1016/j.neuroscience.2009.04.054)

Bailey GS, Poulter RT \& Stockwell PA 1978 Gene duplication in tetraploid fish: model for gene silencing at unlinked duplicated loci. PNAS 75 5575-5579. (doi:10.1073/pnas.75.11.5575)
Barth K \& Wilson S 1995 Expression of zebrafish nk2.2 is influenced by sonic hedgehog/vertebrate hedgehog-1 and demarcates a zone of neuronal differentiation in the embryonic forebrain. Development 121 1755-1768.

Blind E, Wortmann S, Hansen I, Meyer S, Neuner C \& Winkler C 2003 Tuberoinfundibular peptide of 39 residues (TIP39), a ligand of the PTH receptor family may be involved in early brain development in zebrafish. Journal of Bone and Mineral Research 18 S100-S101. (doi:10.1002/jbmr. 5650181304)

Broadus A \& Nissenson R 2006 Parathyroid hormone-related protein. In Primer on the Metabolic Bone Diseases and Disorders of Mineral Metabolism, pp 99-106. Ed. M Favus. Washington, DC: American Society for Bone and Mineral Research.

Catchen J, Conery J \& Postlethwait J 2009 Automated identification of conserved synteny after whole-genome duplication. Genome Research 19 1497-1505. (doi:10.1101/gr.090480.108)

Dehal P \& Boore J 2005 Two rounds of whole genome duplication in the ancestral vertebrate. PLoS Biology 3 e314. (doi:10.1371/journal.pbio. 0030314)

Dobolyi A, Palkovits M, Bodnar I \& Usdin T 2003a Neurons containing tuberoinfundibular peptide of 39 residues project to limbic, endocrine, auditory and spinal areas in rat. Neuroscience 122 1093-1105. (doi:10.1016/j. neuroscience.2003.08.034)

Dobolyi A, Palkovits M \& Usdin T $2003 b$ Expression and distribution of tuberoinfundibular peptide of 39 residues in the rat central nervous system. Journal of Comparative Neurology 455 547-566. (doi:10.1002/cne.10515)

Eichinger A, Fiaschi-Taesch N, Massfelder T, Fritsch S, Barthelmebs M \& Helwig JJ 2002 Transcript expression of the tuberoinfundibular peptide (TIP)39/PTH2 receptor system and non-PTH1 receptor-mediated tonic effects of TIP39 and other PTH2 receptor ligands in renal vessels. Endocrinology 143 3036-3043. (doi:10.1210/en.143.8.3036)

Ekker S, Ungar A, Greenstein P, Kessler DV, Porter J, Moon R \& Beachy P 1995 Patterning activities of vertebrate hedgehog proteins in the developing eye and brain. Current Biology 5 944-955. (doi:10.1016/S0960-9822(95) 00185-0)

Faber C, Dobolyi A, Sleeman M \& Usdin T 2007 Distribution of tuberoinfundibular peptide of 39 residues and its receptor, parathyroid hormone 2 receptor, in the mouse brain. Journal of Comparative Neurology 502 563-583. (doi:10.1002/cne.21330)

Fraser R, Kronenberg H, Pang P \& Harvey S 1990 Parathyroid hormone messenger ribonucleic acid in the rat hypothalamus. Endocrinology $\mathbf{1 2 7}$ 2517-2522. (doi:10.1210/endo-127-5-2517)

Fraser R, Kaneko T, Pang P \& Harvey S 1991 Hypo- and hypercalcemic peptides in fish pituitary glands. American Journal of Physiology $\mathbf{2 6 0}$ R622-R626.

Garcia-Fernandez J \& Holland P 1994 Archetypal organization of the amphioxus Hox gene cluster. Nature 370 563-566. (doi:10.1038/370563a0)

Gardella T \& Jüppner H 2001 Molecular properties of the PTH/PTHrP receptor. Trends in Endocrinology and Metabolism 12 210-217. (doi:10.1016/ S1043-2760(01)00409-X)

Gensure R, Ponugoti B, Gunes Y, Papasani M, Lanske B, Bastepe M, Rubin DA \& Jüppner H 2004 Identification and characterization of two parathyroid hormone-like molecules in zebrafish. Endocrinology 145 1634-1639. (doi:10.1210/en.2003-0964)

Gopinath A, Tseng L \& Whitlock K 2004 Temporal and spatial expression of gonadotropin releasing hormone $(\mathrm{GnRH})$ in the brain of the developing zebrafish (Danio rerio). Gene Expression Patterns 4 65-70. (doi:10.1016/ S1567-133X(03)00149-2)

Guerreiro P, Renfro J, Power D \& Canario A 2007 The parathyroid hormone family of peptides: structure, tissue distribution, regulation, and potential functional roles in calcium and phosphate balance in fish. American Journal of Physiology. Regulatory, Integrative and Comparative Physiology 292 R679-R696. (doi:10.1152/ajpregu.00480.2006)

Guindon S \& Gascuel O 2003 A simple, fast, and accurate algorithm to estimate large phylogenies by maximum likelihood. Systematic Biology $\mathbf{5 2}$ 696-704. (doi:10.1080/10635150390235520)

Guindon S, Lethiec F, Duroux P \& Gascuel O 2005 PHYML Online - a web server for fast maximum likelihood-based phylogenetic inference. Nucleic Acids Research 33 W557-W559. (doi:10.1093/nar/gki352) 
Günther T, Chen ZF, Kim J, Priemel M, Ruegger JM, Amling M, Moseley JM, Martin TJ, Anderson DJ \& Karsenty G 2000 Genetic ablation of parathyroid glands reveals another source of parathyroid hormone. Nature 406 199-203. (doi:10.1038/35018111)

Haldane JBS 1933 The part played by recurrent mutation in evolution. American Naturalist 67 5-9. (doi:10.1086/280465)

Hansen I, Jakob O, Wortmann S, Arzberger T, Allolio B \& Blind E 2002 Characterization of the human and mouse genes encoding the tuberoinfundibular peptide of 39 residues, a ligand of the parathyroid hormone receptor family. Journal of Endocrinology 174 95-102. (doi:10. 1677/joe.0.1740095)

Harvey S \& Hayer S 1993 Parathyroid hormone binding sites in the brain. Peptides 141 1187-1191. (doi:10.1016/0196-9781(93)90174-F)

Herzog W, Zeng Z, Lele Z, Sonntag C, Ting JW, Chang CY \& Hammerschmidt M 2003 Adenohypophysis formation in the zebrafish and its dependence on Sonic hedgehog. Developmental Biology 254 36-49. (doi:10.1016/S0012-1606(02)00124-0)

Herzog W, Sonntag C, Walderich B, Odenthal J, Maischein HM \& Hammerschmidt M 2004 Genetic analysis of adenohypophysis formation in zebrafish. Molecular Endocrinology 18 1185-1195. (doi:10.1210/me.20030376)

Hoare S 2000 G-protein-coupled receptors: what limits high-affinity agonist binding? Trends in Pharmacological Sciences 21 82-83. (doi:10.1016/S01656147(99)01426-1)

Hoare S, Rubin DA, Jüppner H \& Usdin T 2000 Evaluating the ligand specificity of zebrafish parathyroid hormone $(\mathrm{PTH})$ receptors: comparison of PTH, PTH-related protein, and tuberoinfundibular peptide of 39 residues. Endocrinology 141 3080-3086. (doi:10.1210/en.141.9.3080)

Hoegg S, Brinkmann H, Taylor JS \& Meyer A 2004 Phylogenetic timing of the fish-specific genome duplication correlates with the diversification of teleost fish. Journal of Molecular Evolution 59 190-203. (doi:10.1007/s00239004-2613-z)

Hogan B, Danks J, Layton J, Hall N, Heath J \& Lieschke G 2005 Duplicate zebrafish pth genes are expressed along the lateral line and in the central nervous system during embyrogenesis. Endocrinology 146 547-551. (doi:10. 1210/en.2004-0296)

Holland P, Garcia-Fernandez J, Williams N \& Sidow A 1994 Gene duplications and the origins of vertebrate development. Development. Supplement $125-133$.

Jaillon O, Aury J, Brunet F, Petit JL, Stange-Thomann N, Mauceli E, Bouneau L, Fischer C, Ozouf-Costaz C, Bernot A et al. 2004 Genome duplication in the teleost fish Tetradon nigroviridis reveals the early vertebrate proto-karyotype. Nature 431 946-957. (doi:10.1038/nature03025)

John M, Arai M, Rubin DA, Jonsson K \& Jüppner H 2002 Identification and characterization of the murine and human gene encoding the tuberoinfundibular peptide of 39 residues (TIP39). Endocrinology 143 1047-1057. (doi:10.1210/en.143.3.1047)

Joun H, Lanske B, Karperien M, Qian F, Defize L \& Abou-Samra A 1997 Tissue-specific transcription start sites and alternative splicing of the parathyroid hormone $(\mathrm{PTH}) / \mathrm{PTH}$-related peptide $(\mathrm{PTHrP})$ receptor gene: a new $\mathrm{PTH} / \mathrm{PTHrP}$ receptor splice variant that lacks the signal peptide. Endocrinology 138 1742-1749. (doi:10.1210/en.138.4.1742)

Kimmel CB, Ballard WW, Kimmel SR, Ullmann B \& Schilling TF 1995 Stages of embryonic development of the zebrafish. Developmental Dynamics 203 253-310. (doi:10.1002/aja.1002030302)

Kuo MW, Lou SW, Postlethwait JH \& Chung BC 2005 Chromosomal organization, evolutionary relationship, and expression of zebrafish $\mathrm{GnRH}$ family members. Journal of Biomedical Science 389 19-26.

Mangin M, Webb AC, Dreyer BE, Posillico JT, Ikeda K, Weir EC, Stewart AF, Bander NH, Milstone L, Barton DE et al. 1988 Identification of a cDNA encoding a parathyroid hormone-like peptide from a human tumor associated with humoral hypercalcemia of malignancy. PNAS 85 597-601. (doi:10.1073/pnas.85.2.597)

Mannstadt M, Jüppner H \& Gardella TJ 1999 Receptors for PTH and PTHrP: their biological importance and functional properties. American Journal of Physiology 277 F665-F675.
Mathieu J, Barth A, Rosa F, Wilson S \& Peyriéras N 2002 Distinct and cooperative roles for Nodal and Hedgehog signals during hypothalamic development. Development 129 3055-3065.

Merendino JJ, Insogna KL, Milstone LM, Broadus AE \& Stewart AF 1986 Cultured human keratinocytes produce a parathyroid hormone-like protein. Science 231 388-390. (doi:10.1126/science.2417317)

Miao D, He B, Karaplis A \& Goltzman D 2002 Parathyroid hormone is essential for normal fetal bone formation. Journal of Clinical Investigation 109 1173-1182.

Mueller T \& Wullimann M 2003 Anatomy of neurogenesis in the early zebrafish brain. Developmental Brain Research 140 137-155. (doi:10.1016/ S0165-3806(02)00583-7)

Nei M \& Roychoudhury AK 1973 Probability of fixation of nonfunctional genes at duplicate loci. American Naturalist 107 362-372. (doi:10.1086/ 282840)

Papasani M, Gensure R, Yan YL, Gunes Y, Postlethwait J, Ponugoti B, John M, Jüppner H \& Rubin DA 2004 Identification and characterization of the zebrafish and fugu genes encoding tuberoinfundibular peptide 39 (TIP39). Endocrinology 145 5294-5304. (doi:10.1210/en.2004-0159)

Postlethwait J 2007 The zebrafish genome in context: ohnologs gone missing. Journal of Experimental Zoology 308B 563-577. (doi:10.1002/jez.b.21137)

Postlethwait JH, Yan YL, Gates MA, Horne S, Amores A, Brownlie A, Donovan A, Egan ES, Force A, Gong Z et al. 1998 Vertebrate genome evolution and the zebrafish gene map. Nature Genetics 18 345-349. (doi:10. 1038/ng0498-345)

Postlethwait J, Amores A, Force A \& Yan YL 1999 The zebrafish genome. Methods in Cell Biology 60 149-163.

Rodriguez-Mari A, Yan YL, Bremiller R, Wilson C, Canestro C \& Postlethwait J 2005 Characterization and expression pattern of zebrafish anti-mullerian hormone $(\mathrm{Amh})$ relative to sox9a, sox9b, and cyp19a1a, during gonad development. Gene Expression Patterns 5 655-667. (doi:10. 1016/j.modgep.2005.02.008)

Rubin DA \& Jüppner H 1999a Zebrafish express the common PTH/PTHrP receptor (PTH1R) and a novel receptor (PTH3R) that is preferentially activated by mammalian and fugufish parathyroid hormone-related peptide (PTHrP). Journal of Biological Chemistry 274 28185-28190. (doi:10.1074/ jbc.274.40.28185)

Rubin DA \& Jüppner H 1999 b Molecular cloning of cDNAs encoding three distinct receptors for parathyroid hormone (PTH)/PTH-related peptide in the zebrafish. In Calcium Metabolism: Comparative Endocrinology, pp 59-64. Eds J Danks, G Flik \& C Gay. Bristol, UK: BioScientifica Ltd.

Rubin DA, Hellman P, Zon LI, Lobb CJ, Bergwitz C \& Jüppner H 1999 A G protein-coupled receptor from zebrafish is activated by human parathyroid hormone and not by human or teleost parathyroid hormonerelated peptide: implications for the evolutionary conservation of calciumregulating peptide hormones. Journal of Biological Chemistry 274 23035-23042. (doi:10.1074/jbc.274.33.23035)

Schauerte H, Eeden FV, Fricke C, Odenthal J, Strähle U \& Haffter P 1998 Sonic hedgehog is not required for the induction of medial floor plate cells in the zebrafish. Development 125 2983-2993.

Schipani E \& Provot S 2003 PTHrP, PTH, and the PTH/PTHrP receptor in endochondral bone development. Birth Defects Research 69 352-362. (doi:10.1002/bdrc.10028)

Scholpp S, Wolf O, Brand M \& Lumsden A 2006 Hedgehog signalling from the zona limitans intrathalamica orchestrates patterning of the zebrafish diencephalon. Development 133 855-864. (doi:10.1242/dev.02248)

Shoemaker J, Riley L, Hirano T, Grau EG \& Rubin DA 2006 Differential expression of tuberoinfundibular peptide 38 and glucose-6-phosphatase in tilapia. General and Comparative Endocrinology 146 186-194. (doi:10.1016/j. ygcen.2005.10.009)

Spring J 1997 Vertebrate evolution by interspecific hybridisation - are we polyploid? FEBS Letters 400 2-8. (doi:10.1016/S0014-5793(96)01351-8)

Swarthout J, D'Alonzo R, Selvamurugan N \& Partridge N 2002 Parathyroid hormone-dependent signalling pathways regulating genes in bone cells. Gene 282 1-17.

Taylor J, Braasch I, Frickey T, Meyer A \& Van De Peer Y 2003 Genome duplication, a trait shared by 22,000 species of ray-finned fish. Genome Research 13 382-390. (doi:10.1101/gr.640303) 
Tucci J, Russell A, Senior PV, Fernley R, Ferraro T \& Beck F 1996 The expression of parathyroid hormone and parathyroid hormone-related protein in developing rat parathyroid glands. Journal of Molecular Endocrinology 2 149-157. (doi:10.1677/jme.0.0170149)

Usdin TB, Hilton J, Vertesi T, Harta G, Segre G \& Mezey E 1999a Distribution of the parathyroid hormone 2 receptor in rat: immunolocalization reveals expression by several endocrine cells. Endocrinology 140 3363-3371. (doi:10.1210/en.140.7.3363)

Usdin T, Hoare S, Wang T, Mezey E \& Kowalak J 1999b TIP39: a new neuropeptide and PTH2-receptor agonist from hypothalamus. Nature Neuroscience 2 941-943. (doi:10.1038/14724)

Varga Z, Amores A, Lewis K, Yan YL, Postlethwait J, Eisen J \& Westerfield M 2001 Zebrafish smoothened functions in ventral neural tube specification and axon tract formation. Development $\mathbf{1 2 8}$ 3497-3509.

Varga T, Palkovits M, Usdin T \& Dobolyi A 2008 The medial paralemniscal nucleus and its afferent neuronal connections in rat. Journal of Comparative Neurology 511 221-237. (doi:10.1002/cne.21829)

Wang T, Edwards G, Lange G, Parlow A \& Usdin T 2002 Brain administration of tuberoinfundibular peptide of 39 residues inhibits growth hormone secretion. In Recent Research in Developmental Endocrinology, vol 3, pp 317-321. Kerala, India: Transworld Research Network

Wang J, Palkovits M \& Usdin T 2006 Forebrain projections of tuberoinfundibular peptide of 39 residues (TIP39)-containing subparafascicular neurons. Neuroscience 138 1245-1263. (doi:10.1016/j.neuroscience. 2005.12.022)

Ward H, Small C, Murphy K, Kennedy A, Ghatei M \& Bloom S 2001 The actions of tuberoinfundibular peptide on the hypothalamo-pituitary axes. Endocrinology 142 3451-3456. (doi:10.1210/en.142.8.3451)

Watterson GA 1983 On the time for gene silencing at duplicate loci. Genetics $105745-766$.
Weaver DR, Deeds JD, Lee K \& Segre GV 1995 Localization of parathyroid hormone-related peptide (PTHrP) and $\mathrm{PTH} / \mathrm{PTHrP}$ receptor mRNAs in rat brain. Molecular Brain Research 28 296-310. (doi:10.1016/0169$328 X(94) 00222-Z)$

Weir E, Brines M, Ikeda K, Burtis W, Broadus A \& Robbins R 1990 Parathyroid hormone-related peptide gene is expressed in the mammalian central nervous system. PNAS 87 108-112. (doi:10.1073/pnas.87.1.108)

Wolfe K 2000 Robustness - it's not where you think it is. Nature Genetics $\mathbf{2 5}$ 3-4. (doi:10.1038/75560)

Wortmann S, Hansen I, Meyer S, Neuner C, Winkler C, Allolio B \& Blind E 2003. The tuberoinfundibular peptide of 39 residues, a natural ligand of the PTH receptor family, affects early brain development in zebrafish. In Exp. Clin. Endocrinol. Diabetes. Georg Thieme Verlag KG, http://www.thieme. de/eced/abstracts2003/daten/106.html. 106.

Wysolmerski J \& Stewart A 1998 The physiology of parathyroid hormonerelated protein: an emerging role as a developmental factor. Annual Review of Physiology 60 431-460. (doi:10.1146/annurev.physiol.60.1.431)

Yelon D 2001 Cardiac patterning and morphogenesis in zebrafish. Developmental Dynamics 222 552-563. (doi:10.1002/dvdy.1243)

Yelon D, Horne S \& Stainier D 1999 Restricted expression of cardiac myosin genes reveals regulated aspects of heart tube assembly in zebrafish. Developmental Biology 214 23-37. (doi:10.1006/dbio.1999.9406)

Yelon D, Weinstein B \& Fishman M 2002 Aspects of organogenesis: cardiovascular system. In Pattern Formation in Zebrafish, vol 40, pp 298-321. Ed. L Solnica-Krezel. Berlin: Springer-Verlag.

\section{Received in final form 19 August 2011 \\ Accepted 31 August 2011 \\ Made available online as an Accepted Preprint 31 August 2011}

